\title{
The Effects of Amino Acid Nutritional Deficiency on the Expression of Protein Metabolism-Related Genes in the Mammary Gland and Muscle Tissues of Lactating Mice
}

\author{
Xueyan Lin*, Miaomiao Wu*, Guimei Liu, Yun Wang, Qiuling Hou, Kerong Shi, \\ Zhonghua Wang\# \\ College of Animal Science and Technology, Shandong Agricultural University, Tai'an, China \\ Email: linxueyan@sdau.edu.cn, "zhwang@sdau.edu.cn
}

Received 29 June 2015; accepted 21 September 2015; published 24 September 2015

Copyright (C) 2015 by authors and Scientific Research Publishing Inc.

This work is licensed under the Creative Commons Attribution International License (CC BY). http://creativecommons.org/licenses/by/4.0/

\section{(c) () Open Access}

\section{Abstract}

The mammary gland tissue exhibits a series of responses that are different from those of muscle and other peripheral tissues under amino acid deficiency. So, this present study was designed to investigate the effects of amino acid nutritional deficiency on the expression of protein metabolism-related genes in the mammary gland and muscle tissues of lactating mice. A total of 60 postpartum, lactating Kunming white mice were selected and randomly divided into 5 groups; each group contained 12 mice. Group A was the control group. The mice in group A were maintained on a normal diet after the initiation of lactation. Group B (starved) was given normal saline via intragastric administration. Group C (energy) was given glucose solution via intragastric administration. Groups $D$ and $E$ received a sodium caseinate solution via intragastric administration, which provided $0.5 \mathrm{~g}$ protein/d and $1.5 \mathrm{~g}$ protein/d, respectively. The results showed the following. 1) When the mice were exposed to nutritional stress caused by dietary amino acid deficiency, the $\beta$-casein mRNA expression level was increased in the mammary gland tissue. The increase in $\beta$-casein expression was the most significant in the energy-supplemented group, followed by the starved group $(P<0.01)$. In addition, the expression level of myosin heavy chain $2 \mathrm{~A}$ (MHC2a) mRNA was markedly reduced in the muscle tissue $(P<0.05) .2)$ Different dietary treatments significantly affected the mRNA expression of ubiquitin system enzymes such as PolyUbC, E2 ${ }_{14 \mathrm{k}}$ and C2 $(P<0.01)$. The expression levels of the enzymes were upregulated. 3) The blood level of insulin-like growth factor 1 (IGF-1) was significantly decreased in the treatment groups $(P<0.01) .4)$ The phosphorylation level of the p70S6 kinase (p70S6K) was markedly enhanced in the mammary gland tissues collected from the treatment groups $(P<0.05) .5)$ The phosphorylation level of

\footnotetext{
"The authors have equal contribution to this article.

"Corresponding author.

How to cite this paper: Lin, X.Y., Wu, M.M., Liu, G.M., Wang, Y., Hou, Q.L., Shi, K.R. and Wang, Z.H. (2015) The Effects of Amino Acid Nutritional Deficiency on the Expression of Protein Metabolism-Related Genes in the Mammary Gland and Muscle Tissues of Lactating Mice. Advances in Bioscience and Biotechnology, 6, 601-612.

http://dx.doi.org/10.4236/abb.2015.69063
} 
p70S6K was elevated in the muscle tissues collected from the treatment groups. However, the magnitude of the increase was far smaller compared to that in the mammary gland tissues.

\author{
Keywords
}

Amino Acid Nutritional Deficiency, Mammary Gland Tissue, Muscle Tissue, Protein Metabolism

\title{
1. Introduction
}

Under amino acid deficiency, mammary gland tissue exhibits a series of responses that are different from those of muscle and other peripheral tissues. The rate of amino acid uptake from the blood by the mammary gland tissue increases to meet the needs of milk protein synthesis. In contrast, muscle and other tissues degrade proteins and release the deposited amino acids into the blood circulation. Therefore, lactation takes precedence over maintenance metabolism in amino acid and nutrient distribution in the body.

The reasons behind the different responses of mammary gland and muscle tissues are not yet clear. However, some or all of the following aspects may be involved. 1) The types of proteins synthesized by mammary gland and muscle tissues are different. Mammary epithelial cells synthesize exocrine proteins, which are secreted into the extracellular space soon after being synthesized and then are no longer under the cells' control. Muscle cells synthesize their own structural proteins, which are deposited in the cells and can be degraded. 2) The responses of mammary gland and muscle tissues to changes in humoral signals are different. Amino acid deficiency induces changes in the concentrations of amino acids and related hormones in body fluids. The mechanisms of signal reception or sensitivities to the signals are different between mammary gland tissue and muscle tissue, resulting in differences in metabolism. 3) The metabolic regulatory mechanisms are different between the cells of mammary gland and muscle tissues. Both mammary epithelial cells and muscle cells are highly differentiated, but the natures of the cell types are very different. Therefore, differences may exist between the metabolic regulatory mechanisms of the cell types, leading to different responses of the two types of tissues to amino acid deficiency (Bauman et al., 2000; Vernon et al., 1998) [1] [2]. This study was designed to investigate the effects of amino acid nutritional deficiency on the expression of protein metabolism-related genes in the mammary gland and muscle tissues of lactating mice.

\section{Materials and Methods}

\subsection{Experimental Materials}

Clean grade Kunming white mice were purchased from Shandong Taibang Biological Products Co. Ltd., Taian City, China. Trizol reagent was purchased from Invitrogen (Carlsbad, CA, USA). The reverse transcription kit (Code: DRR037A) and real time polymerase chain reaction (PCR) kit (Code: DRR420A) were purchased from TaKaRa Co., Ltd. The primers were purchased from TaKaRa Bio., Inc. The mammalian target of rapamycin (mTOR) antibody (rabbit), phospho-mTOR (P-mTOR) antibody (rabbit), p70S6 kinase (p70S6k) antibody (rabbit), phospho-p70S6k (P-p70S6k) antibody (rabbit), eukaryotic translation initiation factor 4E-binding protein 1 (4EBP1) antibody (rabbit) and phosphor-4EBP1 (P-4EBP1) antibody (rabbit) were all purchased from Cell Signaling Technology, Inc. The cationic amino acid transporter 1 (CAT1) antibody (rabbit) and ASC amino-acid transporter 2 (ASCT2) antibody (rabbit) were purchased from Abcam plc.

\subsection{Experimental Design}

A total of 55 male and 110 female Kunming white mice were selected for the present study. The male and female mice were similar in age (measured in days) and body size. The male mice were housed singly while the female mice were housed together ( 3 female mice per cage) until the mice reached breeding age (male mice at approximately 10 weeks of age and the females at approximately 8 weeks of age). Healthy and active mice were selected and bred at a male-female mating ratio of 1:2. Upon confirmation of breeding success (approximately two weeks after mating), the male mice were removed. The female mice with confirmed pregnancies were housed singly until they gave birth. Starting on the first day of lactation, the female mice were subjected to 1 of 
the 5 different types of treatment described below. Each treatment group contained 12 mice.

Group 1 (control) was fed the normal diet after the initiation of lactation. Group 2 (starved) was given intragastric administrations of $0.5 \mathrm{~mL}$ of normal saline at 7:00 and 19:00 on the first day of lactation and at 7:00 the following day (a total of 3 times). Group 3 (energy) received intragastric administrations of glucose solution (1.1 $\mathrm{g} / \mathrm{mL}$ ) at 7:00, 11:00, 15:00, 19:00 and 23:00 on the first day of lactation and at 7:00, 11:00 and 15:00 the next day (a total of 8 times). The amount of energy provided by the glucose solution was $94.325 \mathrm{KJ} / \mathrm{d}$, which met the energy needs of the mice. Group 4 (low Pro.) received intragastric administrations of sodium caseinate solution $(0.55 \mathrm{~g} / \mathrm{ml})$ at 7:00 on the first day of lactation and at 7:00 the next day (a total of 2 times). The treatment provided $0.5 \mathrm{~g}$ of protein per day, which was insufficient for the protein needs of the mice. Group 5 (high Pro.) received intragastric administrations of sodium caseinate solution $(0.55 \mathrm{~g} / \mathrm{mL})$ at 7:00, 14:00 and 21:00 on the first day of lactation and at 7:00 and 14:00 the next day (a total of 5 times), which provided a total of $1.5 \mathrm{~g}$ protein per day. The mice in all of the treatment groups were fasted but allowed free access to drinking water. The mice were sacrificed at $36 \mathrm{~h}$ after the first intragastric administration (shandong agriculture university animal care and use committee approved this experiment).

\subsection{Sample Collection and Measurement Methods}

\subsubsection{Collection and Examination of Blood Samples}

The mice in all of the treatment groups were caused death by cervical dislocation. Blood samples were collected from the mice, allowed to settle for approximately $30 \mathrm{~min}$ at $4^{\circ} \mathrm{C}$ and then centrifuged at $5000 \mathrm{rpm}$ for $20 \mathrm{~min}$ at $4^{\circ} \mathrm{C}$. The supernatants were collected, transferred to labeled centrifuge tubes, and stored at $-80^{\circ} \mathrm{C}$. The biochemical indices of the blood samples were examined for blood glucose, insulin, insulin-like growth factor 1 (IGF-1), growth hormone (GH) and prolactin (PRL). The hormone indices in the blood samples were analyzed by radioimmunoassay. The blood glucose levels were determined using an automatic biochemistry analyzer.

\subsubsection{Collection and Examination of the Tissue Samples}

After the blood samples were collected from the mice, a ventral midline skin incision was made, and mouse mammary gland tissue in the inguinal region was collected using forceps. In addition, skin was stripped from the hind limbs of the mice, and muscle tissue was collected. The tissue samples were placed into numbered $1.5 \mathrm{~mL}$ centrifuge tubes and quickly stored at $-80^{\circ} \mathrm{C}$. The mRNA expression level of $\beta$-casein in the mammary gland tissue as well as those of $\alpha$-actin, myosin heavy chain I (MHC I), MHC II $\alpha$, MHC IId/x, C2, 14-kDa ubiquitin-conjugating enzyme $\left(\mathrm{E}_{14 \mathrm{k}}\right)$ and polyubiquitin-C (PolyUbC) in the muscle tissue were determined. The phosphorylation levels of mTOR, p70S6k and 4EBP1 and the protein expression levels of ASCT2 and CAT1 were measured in both types of tissues.

\subsubsection{Determination of the Levels of mRNA Expression in Mammary Gland and Muscle Tissues}

In the experiments, glyceraldehyde 3-phosphate dehydrogenase (GAPDH) was utilized as an internal reference. Total RNA was extracted from mammary gland tissue and muscle tissue using the Trizol method. After the quality of the extracted RNA was verified, reverse transcription was conducted in an improved $20 \mu \mathrm{L}$ reaction system using the PrimeScriptTMRT reagent kit (Perfect Real Time) purchased from TaKaRa Co., Ltd. (Code: DRR037A). The steps of the reverse transcription reaction were as follows: $37^{\circ} \mathrm{C}, 15 \mathrm{~min}$; and $85^{\circ} \mathrm{C}, 5 \mathrm{sec}, 1$ cycle.

Fluorescence-based quantitative real-time PCR was performed using the SYBR Green I dye and the SYBR Premix Ex TaqTM (Perfect Real Time) kit purchased from Takara Biotechnology (Dalian) Co., Ltd. (Code: DRR420A). The PCR reaction was conducted on the Applied Biosystems ${ }^{\circledR} 7500$ Real-Time PCR Instrument (USA). The total volume of the reaction was $20 \mu \mathrm{L}$. The sequences of the primers utilized in the PCR reactions are summarized in Table 1.

\subsubsection{Determination of the Levels of Protein Expression in Mammary Gland and Muscle Tissues}

Proteins were extracted from various tissue samples, and the concentrations of total protein were measured. The amount of protein to be loaded was calculated. Based on the calculated results, corresponding amounts of sample loading buffer and lysis buffer were added to the protein samples. The protein samples were then boiled in a denaturing instrument for $5 \mathrm{~min}$ and analyzed by sodium dodecyl sulfate polyacrylamide gel electrophoresis (SDS-PAGE) and western blot. 
Table 1. Primer sequences for each gene.

\begin{tabular}{|c|c|c|c|}
\hline Gene & Primers & Primer sequences ( $5^{\prime} \rightarrow 3^{\prime}$ ) & Product size \\
\hline \multirow[t]{2}{*}{ GAPDH } & Forward & AAGGTGGTGAAGCAGGCAT & 244 bp \\
\hline & Reverse & GGTCCAGGGTTTCTTACTCCT & \\
\hline \multirow[t]{2}{*}{$\beta$-casein } & Forward & TCACTCCAGCATCCAGTCACA & $126 \mathrm{bp}$ \\
\hline & Reverse & GGCCCAAGAGATGGCACCA & \\
\hline \multirow[t]{2}{*}{$\alpha$-actin } & Forward & GTGAGATTGTGCGCGACATC & $156 \mathrm{bp}$ \\
\hline & Reverse & GGCAACGGAAACGCTCATT & \\
\hline \multirow[t]{2}{*}{ MHC I } & Forward & ACAACCCCTACGATTATGCGT & $100 \mathrm{bp}$ \\
\hline & Reverse & ACGTCAAAGGCACTATCCGTG & \\
\hline \multirow[t]{2}{*}{ MHC II $\alpha$} & Forward & CGACAACTCGTCTCGCTTTG & 187 bp \\
\hline & Reverse & CATTTCGATCAGTTCTGGCTTCT & \\
\hline \multirow[t]{2}{*}{ MHCIId/x } & Forward & CACCAGGCTGCTTTAGAGGAA & 207 bp \\
\hline & Reverse & ССТGCTCCTAATCTCAGCATCC & \\
\hline \multirow[t]{2}{*}{ PolyUbC } & Forward & GGCATGCAGATCTTTGTGAA & 265 bp \\
\hline & Reverse & TCTTGCCTGTCAGGGTCTTC & \\
\hline \multirow[t]{2}{*}{$\mathrm{E} 2_{14 \mathrm{k}}$} & Forward & CAGAAGGGACACCCTTTGAA & 306 bp \\
\hline & Reverse & CAATGGCCGAAACTCTCTTC & \\
\hline \multirow[t]{2}{*}{$\mathrm{C} 2$} & Forward & CTTTATGCGCCAGGAGTGTT & $301 \mathrm{bp}$ \\
\hline & Reverse & TTCATCCAAATTGCACTCСА & \\
\hline
\end{tabular}

\subsection{Data Processing and Statistical Analysis}

The experimental data were organized using Excel and subjected to univariate analysis of variance (ANOVA) using the SAS 9.0 software. $P$ values less than 0.05 were considered statistically significant while p values less than 0.01 were considered to be statistically highly significant. All results obtained by statistical analysis were expressed using the mean and standard error.

\section{Results}

\subsection{Effects of Different Dietary Treatments on mRNA Expression Levels in Mammary Gland and Muscle Tissues}

As shown in Table 2, nutritional stress induced by diets deficient in amino acids significantly affected the expression of $\beta$-casein and MHC2 $\alpha(P<0.01, P<0.05)$. The expression level of $\beta$-casein mRNA was enhanced in mammary gland tissues collected from the treatment groups. The most significant increase in $\beta$-casein mRNA expression was observed in mice supplied with only energy, followed by mice in the starved group $(P<0.01)$. $\beta$-casein mRNA expression was also elevated in the rest of the treatment groups. However, the differences were not statistically significant. The experimental treatments did not significantly affect the expression of $\alpha$-actin mRNA in muscle tissue. However, a clear decreasing trend was detected, and the starved group exhibited the largest decrease in $\alpha$-actin mRNA expression. In addition, the expression level of MHC2 $\alpha$ mRNA was significantly reduced in the treatment groups $(P<0.05)$. There were no significant differences in MHC2 $\alpha$ mRNA expression between the treatment groups.

\subsection{Effects of Different Dietary Treatments on mRNA Expression of the Factors of the Ubiquitin System in Muscle Tissue}

It can be observed from Table 3 that different dietary treatments significantly affected the mRNA expression of 
Table 2. Effect of treatment on the mRNA expression of different genes in mammary and muscle tissue.

\begin{tabular}{ccccccccc}
\hline & A & B & C & D & E & SEM & $P$ \\
\hline$\beta$-casein & $150.04^{\mathrm{b}}$ & $230.36^{\mathrm{a}}$ & $257.85^{\mathrm{a}}$ & $156.92^{\mathrm{b}}$ & $165.86^{\mathrm{b}}$ & 18.16 & $<0.01$ \\
$\alpha$-actin & $1.53^{\mathrm{a}}$ & $1.11^{\mathrm{b}}$ & $1.33^{\mathrm{ab}}$ & $1.29^{\mathrm{ab}}$ & $1.40^{\mathrm{ab}}$ & 0.11 & 0.22 \\
MHCI & 0.05 & 0.03 & 0.04 & 0.04 & 0.04 & 0.01 & 0.38 \\
MHC2 $\alpha$ & $0.19^{\mathrm{a}}$ & $0.13^{\mathrm{b}}$ & $0.13^{\mathrm{b}}$ & $0.13^{\mathrm{b}}$ & $0.13^{\mathrm{b}}$ & 0.01 & 0.03 \\
MHC2d/X & 0.24 & 0.21 & 0.30 & 0.29 & 0.32 & 0.03 & 0.22 \\
\hline
\end{tabular}

Note: The experimental data are expressed using the mean and standard error of measurement (SEM). Different letters in superscript following the values in the same row of the table ((a), (b), (c)) indicate statistically significant differences $(P<0.05)$.

Table 3. mRNA level of UPP system genes in muscle tissue.

\begin{tabular}{cccccccc}
\hline & A & B & C & D & E & SEM & $P$ \\
\hline PolyUbC & $0.42^{\mathrm{c}}$ & $0.51^{\mathrm{bc}}$ & $0.62^{\mathrm{b}}$ & $0.59^{\mathrm{b}}$ & $0.76^{\mathrm{a}}$ & 0.04 & $<0.01$ \\
$\mathrm{E} 2_{14 \mathrm{k}}$ & $0.16^{\mathrm{b}}$ & $0.15^{\mathrm{b}}$ & $0.25^{\mathrm{a}}$ & $0.14^{\mathrm{b}}$ & $0.21^{\mathrm{ab}}$ & 0.02 & $<0.01$ \\
$\mathrm{C} 2$ & $0.02^{\mathrm{c}}$ & $0.04^{\mathrm{bc}}$ & $0.12^{\mathrm{a}}$ & $0.04^{\mathrm{bc}}$ & $0.06^{\mathrm{b}}$ & 0.01 & $<0.01$ \\
\hline
\end{tabular}

Note: The experimental data are expressed using the mean and SEM. Different letters in superscript following the values in the same row of the table ((a), (b), (c)) indicate statistically significant differences $(P<0.05)$.

the proteins in the ubiquitin system, including PolyUbC, E2 $2_{14 \mathrm{k}}$ and C2 $(P<0.01)$. Although significant differences existed between some of the treatment groups, the expression levels of PolyUbC, E2 ${ }_{14 \mathrm{k}}$ and C2 were all upregulated. Compared with mice from the starved group, the expression levels of $E 2_{14 \mathrm{k}}$ and $\mathrm{C} 2 \mathrm{mRNAs}$ were highest in mice supplied with energy.

\subsection{Effects of Different Dietary Treatments on the Levels of Hormones and Glucose in the Blood}

Table 4 demonstrates that the blood level of IGF-1 was markedly decreased in the treatment groups in comparison with the normal control group $(P<0.01)$. However, the differences between the treatment groups were not statistically significant. The prolactin (PRL) content was decreased in the starved group but was elevated in the other treatment groups. Again, the differences between the treatment groups were not statistically significant.

\subsection{Effects of Different Dietary Treatments on the Expression Levels of Factors of the mTOR Pathway and Amino Acid Carrier Proteins in Mammary Gland Tissue}

Table 5 showed that the dietary treatments significantly affected the phosphorylation level of p70S6K in the casein synthesis pathway $(P<0.05)$. The phosphorylation level of p70S6K was elevated in all treatment groups. The magnitude of increase was more significant in starved mice and in mice supplied with only energy. The expression level of the Lys/Arg carrier protein CAT1 was increased in the mammary gland tissues collected from the treatment groups $(P<0.05)$. Compared with mice supplied with protein, the magnitude of increase was slightly smaller in the starved mice and in mice supplied with energy. The expression level of the Met carrier protein ASCT2 tended to be decreased. In addition, the phosphorylation levels of mTOR and 4EBP1 were enhanced in the treatment groups. However, the differences were not statistically significant.

\subsection{Effects of Different Dietary Treatments on the Expression Levels of Factors of the mTOR Pathway and Amino Acid Carrier Proteins in Muscle Tissue}

As shown in Table 6, the phosphorylation level of p70S6K, a downstream signaling molecule of the mTOR pathway, was enhanced in muscle tissues collected from mice in almost all treatment groups except the ones supplied with an insufficient amount of protein. However, the magnitude of increase was far smaller compared to that of the mammary gland tissues. In addition, the phosphorylation levels of mTOR and 4EBP1 tended to be 
Table 4. Hormone and glucose levels in the blood.

\begin{tabular}{|c|c|c|c|c|c|c|c|}
\hline & A & B & C & D & E & SEM & $P$ \\
\hline Insulin & 21.31 & 13.57 & 41.06 & 53.96 & 38.58 & 13.44 & 0.23 \\
\hline IGF-1 & $102.84^{\mathrm{a}}$ & $66.98^{\mathrm{b}}$ & $46.48^{\mathrm{b}}$ & $39.01^{\mathrm{b}}$ & $47.10^{\mathrm{b}}$ & 11.01 & $<0.01$ \\
\hline GH & 3.70 & 3.99 & 3.33 & 2.45 & 1.61 & 0.93 & 0.41 \\
\hline PRL & $1.12^{\mathrm{ab}}$ & $0.67^{\mathrm{b}}$ & $1.91^{\mathrm{ab}}$ & $1.90^{\mathrm{ab}}$ & $3.50^{\mathrm{a}}$ & 0.82 & 0.21 \\
\hline Glu & 7.61 & 6.86 & 8.48 & 7.84 & 7.34 & 0.78 & 0.69 \\
\hline
\end{tabular}

Note: The experimental data are expressed using the mean and SEM. Different letters in superscript following the values in the same row of the table ((a), (b), (c)) indicate statistically significant differences $(P<0.05)$.

Table 5. Protein expression of the mTOR pathway and amino acid transporter in mammary tissue.

\begin{tabular}{cccccccc}
\hline & $\mathrm{A}$ & $\mathrm{B}$ & $\mathrm{C}$ & $\mathrm{D}$ & $\mathrm{E}$ & SEM & $P$ \\
\hline mTOR & 1.00 & 0.77 & 0.75 & 0.77 & 0.93 & 0.09 & 0.26 \\
4E & 1.00 & 0.68 & 0.73 & 0.66 & 0.92 & 0.19 & 0.66 \\
p70S6k & 1.00 & 0.74 & 0.83 & 0.64 & 0.73 & 0.13 & 0.39 \\
P-mTOR/mTOR & 1.00 & 1.65 & 3.02 & 2.21 & 2.12 & 0.57 & 0.28 \\
P-4E/4E & 1.00 & 2.22 & 3.87 & 3.44 & 1.88 & 0.92 & 0.23 \\
P-p70/p70 & $1.00^{\mathrm{b}}$ & $1.75^{\mathrm{a}}$ & $1.89^{\mathrm{a}}$ & $1.58^{\mathrm{ab}}$ & $1.39^{\mathrm{ab}}$ & 0.20 & 0.04 \\
ASCT2 & 1.00 & 0.67 & 0.72 & 0.68 & 0.79 & 0.15 & 0.57 \\
CAT1 & $1.00^{\mathrm{b}}$ & $1.17^{\mathrm{ab}}$ & $1.22^{\mathrm{ab}}$ & $1.51^{\mathrm{a}}$ & $1.43^{\mathrm{a}}$ & 0.10 & 0.03 \\
\hline
\end{tabular}

Note: The experimental data are expressed using the mean and SEM. Different letters in superscript following the values in the same row of the table ((a), (b), (c)) indicate statistically significant differences $(P<0.05)$.

Table 6. Protein expression of the mTOR pathway and amino acid transporter in muscle tissue.

\begin{tabular}{cccccccc}
\hline & $\mathrm{A}$ & $\mathrm{B}$ & $\mathrm{C}$ & $\mathrm{D}$ & $\mathrm{E}$ & SEM & $P$ \\
\hline mTOR & 1.00 & 0.88 & 0.73 & 0.67 & 0.59 & 0.17 & 0.49 \\
$4 \mathrm{E}$ & 1.00 & 0.83 & 0.79 & 0.88 & 0.86 & 0.18 & 0.72 \\
p70 & 1.00 & 1.16 & 1.10 & 1.30 & 1.13 & 0.10 & 0.35 \\
P-mTOR/mTOR & 1.00 & 1.35 & 1.35 & 1.38 & 1.70 & 0.35 & 0.74 \\
P-4E/4E & $1.00^{\mathrm{b}}$ & $1.09^{\mathrm{ab}}$ & $1.11^{\mathrm{ab}}$ & $1.26^{\mathrm{a}}$ & $1.17^{\mathrm{ab}}$ & 0.06 & 0.16 \\
P-P70/p70 & $1.00^{\mathrm{bc}}$ & $1.29^{\mathrm{b}}$ & $1.80^{\mathrm{a}}$ & $0.83^{\mathrm{c}}$ & $1.09^{\mathrm{bc}}$ & 0.14 & $<0.01$ \\
ASCT2 & $1.00^{\mathrm{a}}$ & $0.74^{\mathrm{b}}$ & $0.86^{\mathrm{ab}}$ & $0.92^{\mathrm{ab}}$ & $0.80^{\mathrm{b}}$ & 0.05 & 0.04 \\
\hline
\end{tabular}

Note: The experimental data are expressed using the mean and SEM. Different letters in superscript following the values in the same row of the table ((a), (b), (c)) indicate statistically significant differences $(P<0.05)$.

increased. The magnitude of increase was smaller compared with that of the mammary gland tissues. The expression level of the Met carrier protein ASCT2 was reduced in all of the treatment groups $(P<0.05)$, and the largest reduction was observed in the starved group.

The results show that when experiencing dietary amino acid deficiency, lactating mice enhance muscle tissue degradation to preferentially meet the needs of lactation. In mammary gland tissue, the amount of utilized amino acid transporters is elevated, the phosphorylation level of the mTOR pathway is enhanced and the total amount of proteins synthesized is increased. In muscle tissue, the protein phosphorylation level is also increased. However, the amount of utilized amino acid transporters is reduced, the total amount of proteins synthesized is de- 
creased, and protein degradation is enhanced.

Dietary amino acids and energy affect the activity of the ubiquitin-proteasome pathway, which is responsible for muscle tissue degradation. Adequate dietary amino acids and energy may enhance the activity of the pathway.

Hormones significantly affect the protein metabolism in mammary gland and muscle tissues. Among the hormones, the effect of insulin-like growth factors is especially remarkable.

\section{Discussion}

\subsection{Changes in Specialized Proteins and Expression of the Ubiquitin System in Mammary Gland and Muscle Tissues}

The mammary gland displays the highest level of differentiation and the strongest metabolic activity throughout the lactating period [1]. The mammary gland is also one of the two types of tissues that utilize most of the nutrients in the maternal body. As the lactation period starts, the overall nutrient distribution and metabolism of the animals change significantly to meet the needs of the mammary gland. During the lactation period, the nutritional needs of the animals rise to a higher level to support the production of milk. The majority of animal species meet the increasing demand for nutrients by increasing food intake or utilizing nutrients stored in the body. In addition, the metabolism of major nutrients is often altered to provide sufficient nutrients to the mammary gland. In early lactation, many animal species use the body's reserves rather than adjust the food intake to meet the demands of lactation [2]. Protein degradation in muscle tissue is a common metabolic adaptation mechanism employed by animals to provide the required amino acids for the production of milk proteins [1]. Peragon et al. and Hayase et al. reported that the protein turnover in animal organs and tissues is affected by the protein content in the diet [3]. Studies have shown that when the usable energy is sufficient and not restricted by environmental factors, dietary proteins are utilized preferentially to synthesize the somatic proteins, which increase as amino acid intake increases. The continuous increase in amino acid intake results in a decreased protein deposition rate in the body. Low-protein diets reduce the relative rate of total protein synthesis and significantly enhance the rate of total protein reutilization, thereby promoting protein deposition [4].

In the present study, lactating mice were exposed to amino acid deficiency-induced nutritional stress. No significant decrease in casein secretion was detected in the short term even though the nutrition or energy supply is lacking. On the contrary, the expression of the casein gene was upregulated, which suggested that mammary gland tissue might achieve protein turnover and ensure the priority of lactation through the degradation of muscle tissues. The level of casein secretion was slightly higher in mice supplied with a sufficient amount of protein compared to the mice supplied with a low amount of protein. Judging from the changes in the expression level of specialized genes, there was no clear evidence that the amount of protein provided post starvation would affect the level of casein synthesis. The expression levels of the casein gene were significantly decreased in mice from both the low protein and the high protein groups compared to the mice from the starved group, while the expression level of the casein gene was lower in starved mice compared to the mice supplied with only energy. The expression level of the MHC2 $\alpha$ gene, which encodes one of the myosin heavy chain isoforms, was decreased in the muscle tissues $(P<0.05)$, indicating that the protein content of the muscle tissues was reduced. However, the results were not sufficient to prove whether the decrease was due to elevated protein degradation or due to reduced protein synthesis. Research conducted by Varshavsky et al. showed that the ubiquitin-proteasome proteolytic pathway is the primary pathway of muscle protein degradation in various consumptive diseases (including starvation, infections, diabetes, burns and metabolic acidosis) [5]. The main components of the ubiquitin pathway are the ubiquitins and the 26S proteasome complex. The 20S proteasome is the catalytic core of the 26S proteasome complex. Therefore, this study examined the mRNA expression of the components related to the ubiquitin-proteasome pathway. The results showed that the expression levels of PolyUbC, ubiquitin-conjugating enzyme $\mathrm{E} 2_{14 \mathrm{k}}$ and the $\mathrm{C} 2$ subunit of the $20 \mathrm{~S}$ proteasome were all upregulated $(P<0.01)$. Previous studies have demonstrated that the expression of genes in the ubiquitin system is positively correlated with the activity of the system. The inhibition of expression of the subunit genes significantly reduces the content and activity of the proteasomes in cells [6]. The findings described above provide a powerful explanation for our results that protein degradation was elevated in muscle tissues.

A study performed by Emery et al. showed that if the net energy provided by grain or roughage increases by 4.18 MJ, the total milk protein content will increase correspondingly by 0.015 units. Furthermore, each addi- 
tional $1 \mathrm{MJ}$ of metabolic energy provided by the diet will result in an increase of 0.03 units in total milk protein content [7]. The above findings indicate that milk protein content is positively correlated with energy intake $(\mathrm{r}=$ 0.42). Sporndly et al. have identified a positive correlation between milk protein content and metabolizable energy intake $(r=0.42, r=0.31)$, suggesting that milk protein content is primarily affected by dietary energy levels [8]. The present study showed that the expression level of the casein gene was the highest in mammary gland tissue collected from mice supplied with energy only in comparison to mice from the control group and other treatment groups. Our result was consistent with the findings of the above studies. The mRNA expression of the specialized genes in muscle tissue was examined. and the results showed that when the lactating mice were provided only with sufficient energy, the protein content in the muscle tissue decreased significantly $(P<$ 0.05). The magnitude of the decrease was larger than that of the group of mice provided with protein. The results indicated that compared with the protein factor, the energy factor may exert a more significant effect on protein turnover and metabolism in the mammary gland and muscle tissues.

In animals, the efficiency of protein turnover and metabolism is significantly affected by the level of dietary energy intake. Kita et al. conducted a study in which the protein level was kept constant and the metabolizable energy level was adjusted gradually from a state of deficiency to a state that met the needs of the animals. Kita et al. [9] found that the rates of whole-body protein synthesis and degradation were elevated in the animals. When dietary energy level was further increased to exceed the needs of the animals, the protein synthesis rate remained constant. In contrast, insufficient dietary energy intake resulted in limited protein synthesis in the animal's body. However, the mechanisms by which energy intake affects protein turnover are not yet clear. Wu et $a l$. has proposed that as the protein deposition rate increases, the energy cost per gram of protein deposition will increase accordingly. Insufficient energy intake has little effect on the protein synthesis rate, protein synthesis capability and protein synthesis efficiency in animal tissues and the body. However, insufficient energy intake results in an enhanced rate of muscle protein degradation, which provides amino acids for oxidative reaction and energy production. In the present study, the mRNA expression levels of the factors related to the ubiquitin-proteasome pathway were significantly increased $(P<0.01)$. Except for PolyUbC, the mRNA expression levels of the other examined factors increased the most in mice provided with only energy, suggesting that sufficient energy would promote the activity of the ubiquitin-proteasome proteolytic pathway. In addition, significant differences were observed in the mRNA expression of factors related to the ubiquitin-proteasome pathway between different treatment groups. These results suggested that compared with the starvation treatment, the supply of protein may enhance the activity of the ubiquitin-proteasome proteolytic pathway and muscle tissue degradation and the magnitude of enhancement may be larger when adequate amounts of protein were provided in comparison to an insufficient protein supply.

\subsection{Changes in Hormone Levels}

In the present study, the blood hormone levels of lactating mice were examined, and the results showed that the level of GH was slightly elevated in the blood of the mice from the starved group. However, the difference was not statistically significant. Analysis of the expression of the casein gene showed that its expression level was increased in the starved group. A significant number of studies have confirmed that GH exerts a strong lactation-promoting effect and is capable of enhancing milk yield in dairy cows [10] [11]. Sakamoto et al. [12] found that in the absence of prolactin and insulin, GH acts directly on secretory epithelial cells in mammary glands and increases the expression of casein at both the gene and protein levels. Molento et al. found that the unique nutritional distribution function of GH in the body allows more nutrients to be allocated to the mammary gland [13]. GH promotes the secretion of IGF-1 [14]. In dairy cows, the blood level of IGF-1 is often positively correlated with milk yield [15]. Using mammary tissues or mammary epithelial cells of dairy cows as experimental models, Sakamoto et al. demonstrated at the cell and tissue levels that GH promotes the synthesis of $\alpha$ s casein and the expression of the $\beta$-casein gene [12]. Furthermore, studies conducted by Glimm et al. and Baumrucker et al. confirmed the presence of GH and IGF-1 receptors in the mammary tissue of dairy cows [16] [17]. Therefore, GH may exert its effect either by directly acting on mammary glands or by stimulating the secretion of IGF-1, thus indirectly affecting mammary glands.

A study by Prosser and Davis showed that the infusion of IGF-1 into the external pudendal artery significantly increased blood flow in mammary glands and elevated the secretion of mammary gland milk [18]. In addition, a study performed by Burgos et al. showed that IGF-1 promotes protein synthesis in the mammary epithelial cells 
of dairy cows [19]. Dohm et al. found that IGF-1 displays a strong promoting effect on the development and anabolism of skeletal muscles and other organs [4]. IGF-1 exerts its effects on skeletal muscle through IGF-1 receptors. By binding to its receptors, IGF-1 promotes the proliferation and differentiation of skeletal muscle cells, increases amino acid and glucose uptake in skeletal muscle cells, stimulates protein synthesis in skeletal muscle and inhibits protein degradation, thereby enhancing the net protein deposition in skeletal muscle. Studies have also shown that patients with protein malnutrition tend to have low levels of IGF-1. Liu et al. found that the IGF-1 concentration in bovine blood is related to dietary nutrient levels and dietary intake. The IGF-1 concentration is positively correlated with the concentration of casein in the diet. Some scholars have reported that the main factor affecting the blood concentration of IGF-1 is the crude protein level, and the response of IGF-1 to the crude protein level is affected by the metabolizable energy concentration in the diet. A study conducted by Conlon et al. showed that that plasma IGF-1 concentration is strongly correlated with the plasma concentrations of nutrients [20]. The plasma IGF-1 concentration is decreased in fasting table poultry, and this decrease is accompanied by a reduced rate of pectoralis muscle protein synthesis. The plasma IGF-1 concentration returns to normal after supplementary feeding. Broiler chickens at 7 days of age were given intramuscular injections of IGF-1 (35 mg/chicken). At $6 \mathrm{~h}$ after injection, the relative rate of pectoral muscle protein synthesis was significantly elevated, and the relative rate of the protein degradation was reduced, resulting in increased daily weight gain and nitrogen deposition. Comparing the two treatment groups in the present study that were supplied with proteins, the high protein group showed a IGF-1 level higher than that of the low protein group, which is consistent with the findings described above. Breier et al. conducted a study of beef cattle and found that the plasma concentration of IGF-1 decreases only when the cattle are in a state of negative energy balance [21]. A study conducted by Williams et al. showed that improvement of dietary energy levels leads to a linear increase in the blood concentrations of insulin and IGF-1 in primiparous heifers [22]. The present study showed that IGF-1 levels were markedly decreased in starved mice and in mice supplied with energy only $(P<0.01)$. In addition, the degradation of muscle tissue was increased. These results were consistent with the findings of the previous studies described above. However, the present study failed to detect any increase in the IGF-1 level in mice supplied with energy in comparison to the starved mice, which is inconsistent with the general theory.

Spomdly et al. utilized the hyperinsulinemic-euglycemic clamp technique to study the function of insulin [8]. The results have shown that the application of insulin leads to significantly increased milk protein content and yield. In nutritionally adequate cattle, the milk protein yield is increased by $25 \%$. These results suggest that insulin is a major endocrine regulatory factor controlling milk protein synthesis. In the present study, all of the treatment groups except for the starved group exhibited increased insulin content. However, no statistically significant differences were detected between the groups. A study performed by Canfield and Butler showed that insulin is an important hormone regulating carbohydrate, fat and protein metabolism and maintaining stable blood sugar levels [11]. Insulin usually reflects the comprehensive balance between feed intake and milk yield. The insulin concentration is greatly affected by the energy levels. Insulin is a hormone that reflects the energy status of the body. In the present study, the changes in the insulin levels were not statistically significant. However, compared with the normal control group, the blood level of insulin was decreased after starvation and increased when sufficient energy was supplied, indicating that insulin reflected the energy status of the body.

\subsection{Phosphorylation Levels of the Effectors of the mTOR Pathway and Expression Levels of Carrier Proteins in Mammary Gland and Muscle Tissues}

Studies have shown that once phosphorylated and activated, mTOR controls the translation of mRNAs in a specific subgroup through two disparate downstream pathways, the 4E-BP1 and the p70S6K pathways, and subsequently increases protein synthesis. In the present study, the phosphorylation levels of mTOR and 4EBP1 were elevated in mammary gland tissue. However, the changes were not statistically significant. In contrast, the downstream signaling molecule of mTOR, p70S6K, demonstrated a markedly increased phosphorylation level $(P<0.05)$. These results were consistent with the findings described previously that the expression of the casein gene was upregulated. Similarly, the phosphorylation levels of mTOR and 4EBP1 were also elevated in muscle tissue, but the differences were statistically insignificant. In addition, the increase in the muscle tissue was significantly smaller than that in the mammary gland tissue. The phosphorylation level of p70S6K was markedly elevated, whereas it was significantly decreased when an insufficient amount of protein was supplied $(P<0.01)$.

Research conducted by Humphrey et al. indicated that the adaptive response of animal tissues to different dietary components and nutrient levels is primarily reflected by changes in the type and amount of the transporters 
of the nutrients in the body. The chemical composition of the diet directly or indirectly affects the expression of the transporters [23]. As an increasing number of cDNA sequences encoding mammalian amino acid transporters have been cloned, many studies have focused on the regulatory effect of dietary nutrient composition on the expression of amino acid transporters. Dietary nutrient levels, especially the protein (amino acid) levels, affect the regulation of amino acid transporter expression. To maintain cell survival under the conditions of amino acid deficiency, protein catabolism is increased in muscle cells, amino acid biosynthesis is elevated and an increasing amount of amino acids is transported across the membrane into the cells. In addition, the synthesis of the transporter protein CAT-1 is enhanced. The levels of insulin and other hormones significantly affect the expression of the amino acid transporters. Simmons et al. treated quiescent muscle cells with a 10 -fold increase of interleukin-1 beta (IL-1 $\beta$ ) and interferon gamma (IFN- $\gamma$ ) and found that the expression level of CAT-1 mRNA was elevated. Under the action of cytokines, the expression level of CAT-1 mRNA was also increased. Shi et al. employed an animal model to investigate for the first time the effect of daily diet on the level of CAT-1 expression in pig intestine. Studies have shown that compared with a high protein diet, a low protein diet has a bigger impact on the relative expression level of CAT-1 mRNA in the intestine of fattening pigs, especially in the jejunum. Using an in vitro culture method, Zhi et al. found that the abundance of CAT-1 mRNA expression increases as the lysine concentration increases. The difference was highly significant and dose-dependent. The present study showed that the expression of the Lys/Arg transporter CAT-1 was drastically elevated in mammary gland tissue $(P<0.05)$. Moreover, the increase in CAT-1 expression was more significant in mice supplied with protein after starvation compared to mice supplied with energy.

In a study that employed BeWo cells as the experimental model, it was shown that changes in the substrate concentration affect the mRNA expression of a number of amino acid transporters. However, the tendency to increase or decrease varies among the transporters. Jones et al. found that essential amino acid deficiency in the body leads to a significantly decreased expression of sodium-coupled neutral amino acid transporter 1 (SNAT1) mRNA within $1 \mathrm{~h}$. However, no obvious changes in sodium-coupled neutral amino acid transporter 2 (SNAT2) mRNA expression are detected within $1 \mathrm{~h}$. In contrast, the level of SNAT2 mRNA increases at or after $3 \mathrm{~h}$. Furthermore, the level of SNAT2 mRNA expression is markedly elevated when the supply of amino acids increases [24]. Lys and Met are two major limiting amino acids for growth and milk protein synthesis. The present study showed that the expression level of the Met transporter protein ASCT2 was significantly reduced in muscle tissue $(P<0.05)$. These results indicated that the amount of transporter protein was decreased, which might lead to declined protein synthesis in the muscle tissue. Compared with the starved group, mice that were given dietary protein showed a slightly decreased level of ASCT2. The results were consistent with findings from previous studies showing that the substrate concentration affects the expression of amino acid transporters.

Energy metabolism is a very complex process. The mTOR signaling pathway is involved in the regulation of energy homeostasis. Energy-producing substances participate in energy regulation primarily through the liver kinase B1 (LKB1)-adenine monophosphate-activated protein kinase (AMPK)-tuberous sclerosis complex (TSC)mTOR signaling pathway. AMPK is a sensor of cellular energy levels. Intracellular energy deficiency activates the AMPK protein. Activated AMPK inhibits mTOR activity and subsequently initiates ATP synthesis and prevents ATP consumption, ceasing cell growth. When sufficient energy is available, AMPK functions as a "switch" to shut down the energy supply and ensures that the energy is released and utilized to promote cell growth. In addition, changes in the activation state of AMPK affect the activity and phosphorylation level of p70S6K, a downstream signaling molecule of mTOR, which will further affect mRNA translation in somatic animal cells and control protein synthesis. The hypothalamus senses changes in energy balance through the mTOR pathway and controls food intake through feedback mechanisms, thus contributing to the achievement of energy homeostasis in the body. Abnormal mTOR signaling leads to disorders of energy metabolism. Excessive food intake-induced obesity has been observed in TSC1-knockout mice. Sobolewska et al. found that IGF-1 and epidermal growth factor (EGF) activate mTOR in bovine mammary epithelial cells, whereas the inhibition of mTOR by rapamycin abolishes the inhibitory effect of IGF-1 and EGF on autophagy [25]. AMPK achieves its role as a sensor of cellular energy status through the negative regulation of mTOR. Bolster et al. found that the injection of rats with energy-providing substances does not alter AMPK $\alpha 1$ activity in gastrocnemius muscle. However, AMPK $\alpha 2$ activity was significantly enhanced [26]. Compared with the control group, muscle protein synthesis was reduced by $45 \%$ in the treatment group because the downregulation of mTOR by AMPK directly inhibits translation initiation and protein synthesis. Kimura et al. [27] treated human corneal epithelial cells with AMPK activator and found that the activity and phosphorylation of p70S6K, a downstream signaling factor of 
mTOR, are suppressed. In addition, changes in glucose concentration also regulate the activity of AMPK and p70S6K. In the present study, p70S6K phosphorylation in both types of tissue was elevated in the starved group in comparison with the normal treatment group. However, the magnitude of increase was significantly lower in the muscle tissue compared to that in the mammary gland tissue. Compared with the starved group, mice supplied with sufficient energy showed an increased level of p70S6K phosphorylation in both types of tissues $(P<$ $0.05, P<0.01$ ), which is consistent with previously published results.

\section{Conclusions}

When experiencing dietary amino acid deficiency, lactating mice enhance muscle tissue degradation to preferentially meet the needs of lactation. In mammary gland tissue, the amount of utilized amino acid transporters is elevated, the phosphorylation level of the mTOR pathway is enhanced and the total amount of proteins synthesized is increased. In muscle tissue, the protein phosphorylation level is also increased. However, the amount of utilized amino acid transporters is reduced, the total amount of proteins synthesized is decreased, and protein degradation is enhanced.

Dietary amino acids and energy affect the activity of the ubiquitin-proteasome pathway, which is responsible for muscle tissue degradation. Adequate dietary amino acids and energy may enhance the activity of the pathway.

Hormones significantly affect the protein metabolism in mammary gland and muscle tissues. Among the hormones, the effect of insulin-like growth factors is especially remarkable.

\section{Acknowledgements}

Financial support was provided by the fund for Modern Agro-industry Technology Research System of China (CARS-37, Modern Agro-industry Technology Research System of Shandong (SDAIT-12-011-06)), Shandong province science technology development plan (2012NC11103), natural science fund of China (31072050) (31372340) and cattle breed project of Shandong province.

\section{References}

[1] Bauman, D.E. (2000) Ruminant Physiology: Digestion, Metabolism, Growth and Reproduction. CAB International, Souse Africa, 311-328.

[2] Vernon, R.G. (1998) Homeorhesis. In: Research Reviews, Hannah Yearbook, Hannah Research Institute, Ayr, UK, 6473.

[3] Peragón, J., Barroso, J.B., García-Salguero, L., et al. (1994) Dietary Protein Effects on Growth and Fractional Protein Synthesis and Degradation Rates in Liver and White Muscle of Rainbow Trout. Aquaculture, 124, 35-46. http://dx.doi.org/10.1016/0044-8486(94)90352-2

[4] Dohm, G.L., Elton, C.W., Raju, M.S., et al. (1990) IGF-I-Stimulated Glucose Transport in Human Skeletal Muscle and IGF-I Resistance in Obesity and NIDDM. Diabetes, 39, 1028-1032. http://dx.doi.org/10.2337/diab.39.9.1028

[5] Varshavsky, A. (1997) The N-End Rule Pathway of Protein Degradation. Genes to Cells, 2, 13-28. http://dx.doi.org/10.1046/j.1365-2443.1997.1020301.x

[6] Grune, T., Blasig, I.E. and Sitte, N. (1998) Peroxynitrite Increases the Degradation of Aconitase and Other Cellular Proteins by Proteasome. Journal of Biological Chemistry, 273, 10857-10862. http://dx.doi.org/10.1074/jbc.273.18.10857

[7] Emery, R.S. (1978) Feeding for Increased Milk Protein. Journal of Dairy Science, 61, 825-828. http://dx.doi.org/10.3168/jds.S0022-0302(78)83656-X

[8] Sporndly, E. (1989) Effects of Diet on Milk Composition and Yield of Dairy Cows with Special Emphasis on Milk Protein Content. Swedish Journal of Agricultural Research, 19, 99-106.

[9] Wu, X.L. and Ying, F. (2002) Research Method and Model of Animal Protein Business Turnover. Journal of Nuclear Agriculture Science, 16, 156-161.

[10] Lough, D.S., Muller, L.D., Kensinger, R.S., et al. (1989) Effect of Exogenous Bovine Somatotropin on Mammary Lipid Metabolism and Milk Yield in Lactating Dairy Cows. Journal of Dairy Science, 72, 1469-1476. http://dx.doi.org/10.3168/jds.S0022-0302(89)79256-0

[11] Canfield, R.W. and Butler, W.R. (1990) Energy Balance and Pulsatile LH Secretion in Early Postpartum Dairy Cattle. Domestic Animal Endocrinology, 7, 323-330. http://dx.doi.org/10.1016/0739-7240(90)90038-2 
[12] Sakamoto, K., Komatsu, T., Kobayashi, T., Rose, M.T., Aso, H., Hagino, A. and Obara, Y. (2005) Growth Hormone Acts on the Synthesis and Secretion of $\alpha$-Casein in Bovine Mammary Epithelial Cells. Journal of Dairy Research, 72, 264-270. http://dx.doi.org/10.1017/S0022029905000889

[13] Molento, C.F.M., Block, E., Cue, R.I. and Petitclerc, D. (2002) Effects of Insulin, Recombinant Bovine Somatotropin, and Their Interaction on Insulin-Like Growth Factor-I Secretion and Milk Protein Production in Dairy Cows. Journal of Dairy Science, 85, 738-747. http://dx.doi.org/10.3168/jds.S0022-0302(02)74131-3

[14] Bauman, D.E. (1999) Bovine Somatotropin and Lactation: From Basic Science to Commercial Application. Domestic Animal Endocrinology, 17, 101-116. http://dx.doi.org/10.1016/S0739-7240(99)00028-4

[15] Rose, M.T., Weekes, T.E.C. and Rowlinson, P. (2005) Correlation of Blood and Milk Components with the Milk Yield Response to Bovine Somatotropin in Dairy Cows. Domestic Animal Endocrinology, 28, 296-307. http://dx.doi.org/10.1016/j.domaniend.2004.12.001

[16] Glimm, D.R., Baracos, V.E. and Kennelly, J.J. (1990) Molecular Evidence for the Presence of Growth Hormone Receptors in the Bovine Mammary Gland. Journal of Endocrinology, 126, R5-R8. http://dx.doi.org/10.1677/joe.0.126R005

[17] Baumrucker, C.R. and Erondu, N.E. (2000) Insulin-Like Growth Factor (IGF) System in the Bovine Mammary Gland and Milk. Journal of Mammary Gland Biology and Neoplasia, 5, 53-64. http://dx.doi.org/10.1023/A:1009515232450

[18] Prosser, C.G., Davis, S.R., Farr, V.C., Moore, L.G. and Gluckman, P.D. (1994) Effects of Close-Arterial (External Pudic) Infusion of Insulin-Like Growth Factor-II on Milk Yield and Mammary Blood Flow in Lactating Goats. Journal of Endocrinology, 142, 93-99. http://dx.doi.org/10.1677/joe.0.1420093

[19] Burgos, S.A. and Cant, J.P. (2010) IGF-1 Stimulates Protein Synthesis by Enhanced Signaling through mTORC1 in Bovine Mammary Epithelial Cells. Domestic Animal Endocrinology, 38, 211-221. http://dx.doi.org/10.1016/j.domaniend.2009.10.005

[20] Conlon, M.A. and Kita, K. (2002) Muscle Protein Synthesis Rate Is Altered in Response to a Single Injection of Insulin-Like Growth Factor-I in Seven-Day-Old Leghorn Chicks. Poultry Science, 81, 1543-1547. http://dx.doi.org/10.1093/ps/81.10.1543

[21] Breier, B.H., Bass, J.J., Butler, J.H. and Gluckman, P.D. (1986) The Somatotrophic Axis in Young Steers: Influence of Nutritional Status on Pulsatile Release of Growth Hormone and Circulating Concentrations of Insulin-Like Growth Factor 1. Journal of Endocrinology, 111, 209-215. http://dx.doi.org/10.1677/joe.0.1110209

[22] Williams, N.G., Interlichia, J.P., Jackson, M.F., Hwang, D., Cohen, P. and Rodgers, B.D. (2011) Endocrine Actions of Myostatin: Systemic Regulation of the IGF and IGF Binding Protein Axis. Endocrinology, 152, 172-180. http://dx.doi.org/10.1210/en.2010-0488

[23] Humphrey, B.D., Stephensen, C.B., Calvert, C.C. and Klasing, K.C. (2004) Glucose and Cationic Amino Acid Transporter Expression in Growing Chickens (Gallus gallus domesticus). Comparative Biochemistry and Physiology Part A: Molecular \& Integrative Physiology, 138, 515-525. http://dx.doi.org/10.1016/j.cbpb.2004.06.016

[24] Jones, H.N., Ashworth, C.J., Page, K.R. and McArdle, H.J. (2006) Cortisol Stimulates System A Amino Acid Transport and SNAT2 Expression in a Human Placental Cell Line (BeWo). American Journal of Physiology-Endocrinology and Metabolism, 291, E596-E603. http://dx.doi.org/10.1152/ajpendo.00359.2005

[25] Sobolewska, A., Gajewska, M., Zarzyńska, J., Gajkowska, B. and Motyl, T. (2009) IGF-I, EGF, and Sex Steroids Regulate Autophagy in Bovine Mammary Epithelial Cells via the mTOR Pathway. European Journal of Cell Biology, 88, 117-130. http://dx.doi.org/10.1016/j.ejcb.2008.09.004

[26] Bolster, D.R., Crozier, S.J., Kimball, S.R. and Jefferson, L.S. (2002) AMP-Activated Protein Kinase Suppresses Protein Synthesis in Rat Skeletal Muscle through Down-Regulated Mammalian Target of Rapamycin (mTOR) Signaling. Journal of Biological Chemistry, 277, 23977-23980. http://dx.doi.org/10.1074/jbc.C200171200

[27] Kimura, N., Tokunaga, C., Dalal, S., Richardson, C., Yoshino, K., Hara, K., et al. (2003) A Possible Linkage between AMP-Activated Protein Kinase (AMPK) and Mammalian Target of Rapamycin (mTOR) Signalling Pathway. Genes to Cells, 8, 65-79. http://dx.doi.org/10.1046/j.1365-2443.2003.00615.x 